Article

\title{
New Second-Order Sliding Mode Control Design for Load Frequency Control of a Power System
}

\author{
Van Van Huynh ${ }^{1}$, Phong Thanh Tran ${ }^{1, *}$, Bui Le Ngoc Minh ${ }^{2}$, Anh Tuan Tran ${ }^{1}$, \\ Dao Huy Tuan ${ }^{1}$, Tam Minh Nguyen ${ }^{2}$ and Phan-Tu Vu ${ }^{3}$ \\ 1 Faculty of Electrical \& Electronics Engineering, Ton Duc Thang University, \\ Ho Chi Minh City 700000, Vietnam; huynhvanvan@tdtu.edu.vn (V.V.H.); \\ trananhtuan.st@tdtu.edu.vn (A.T.T.); daohuytuan@tdtu.edu.vn (D.H.T) \\ 2 Faculty of Electrical and Electronics Engineering, Ho Chi Minh City University of Technology and Education, \\ Ho Chi Minh City 700000, Vietnam; 1726002@student.hcmute.edu.vn (B.L.N.M.); \\ tamnm@hcmute.edu.vn (T.M.N.) \\ 3 Department of Power Systems of Ho Chi Minh City University of Technology, Vietnam National University, \\ Ho Chi Minh City 700000, Vietnam; vptu@vnuhcm.edu.vn \\ * Correspondence: tranthanhphong.st@tdtu.edu.vn; Tel.: +84-936967379
}

Received: 19 September 2020; Accepted: 3 December 2020; Published: 9 December 2020

check for updates

\begin{abstract}
The implementation of the sliding mode control (SMC) for load frequency control of power networks becomes difficult due to the chattering phenomenon of high-frequency switching. This chattering problem in SMC is extremely dangerous for actuators used in power systems. In this paper, a continuous control strategy by combining a second-order mode and integral siding surface is proposed as a possible solution to this problem. The proposed second-order integral sliding mode control (SOISMC) law not only rejects chattering phenomenon in control input, but also guarantees the robustness of the multi-area power network, which has an effect on parametric uncertainties such as the load variations and the matched or mismatched parameter uncertainties. Moreover, the reporting of the simulation indicates that the proposed controller upholds the quality requirement by controlling with operating conditions in the larger range, rejects disturbance, reduces the transient response of frequency, eliminates the overshoot problem, and can better address load uncertainties compared to several previous control methods. The simulation results also show that the proposed SOISMC can be used for practical multi-area power network to lessen high parameter uncertainties and load disturbances.
\end{abstract}

Keywords: load frequency control; multi-area power system; second order sliding mode control

\section{Introduction}

In general terms, a power network includes a connection of electrical components that can be divided into a generator that supply the power, the transmission system that inducts the power to the load from the centers of electricity generation, and the distribution system that supply the power to neighboring industries, hospitals, homes and the other kinds of load [1,2]. Therefore, different load changes continuously and progressively occur with the demand of reactive and active power by the neighboring industries, homes etc. In practical power networks, the frequency deviation is caused by increasing real power demand and the voltage as well is impacted by variation of reactive power. To continue meeting the real power demands, the load frequency needs to be controlled. The principal standard of the load frequency control (LFC) is to keep the frequency of power system and voltage uniform at its nominal value during and when there is load change. In A conventional power system, governor droop speed control and auxiliary back-up control are used to regulate frequency 
(i.e., frequency controllers) while automatic voltage regulates (AVR) for the voltage supply by many power companies. Since the inception of interconnected multi-area power networks, they have become more economical and reliable. The big challenges with the proposed control design, especially for LFC in tie multi-area power network, are a great deal of problems such as unpredicted external disturbances, parameters of uncertainties and even the nonlinear model of uncertainties in power systems. However, the targets of LFC are to keep at minimum the transient response deviations in each area frequency and interchange of tie-line power and to guarantee their steady state errors to be zero. LFC normalizes the frequency of power system, enables to maintain system dynamics, and provides certain conditions to ensure quality assurance of the power supply [3-5].

In literature, there are many control schemes such as proportion integration derivative (PID) control, internal model control scheme, model predictive model control, fuzzy logic method, artificial intelligence control, SMC and so on that have been discussed. The topics have been introduced in [6-30]. In a prescribed power network environment, the above mentioned-LFC approaches with matched and mismatched uncertainties elements are used in a power system. The proposed PID-type controllers apply to present several control models in [6-9]. In [6,7], the linear algebraic equations have been used in these methods to find controller parameters. Based on the direct synthesis scheme and chaotic algorithm method were given in frequency domain to finalize and optimize the method of PID controller for interconnected power network. The extended controller of PID method by using the low pass filter was a strategy of tuning its way in [8]. The differential evolutionary scheme using a parallel two-degree freedom of the PID controller for LFC of the power network was incorporated into a power system in [9]. Nevertheless, most traditional PID controller methods with fixed gain were designed under normal operating conditions of power systems. In addition, these proposed approaches were always used in tuning or selecting modes, such as the fundamental method of trial and error without analytical methods for determining and optimizing the parameters of interconnected multi-area power networks. Therefore, it is very difficult to find out the best proposed control schemes to finalize the good performance in larger range of the practical operating conditions. Beside PID control techniques mentioned above, the model predictive control or fuzzy logic control or intelligent control is one of the best options. To reduce the regulation burden of the control area without regulation capacity, the proposed cooperative based on differential games was designed for supplying the power via tie-line between two areas of the power systems [10]. In [11], the scheme of LFC for power systems was suggested and developed based on the direct adaptive fuzzy logic method. The suggestion of model predictive controller for LFC was investigated and developed in [12]. In deregulated environments [13], a model predictive controller for LFC for the power system introduced a Kalman filter for state estimation with a linear active disturbance rejection scheme method to evaluate and quickly repay the disturbances. The simple scheme to LFC control design for power networks with parametric uncertainties and load disturbances was represented in [14]. In [15], this paper was presented by an internal adaptive LFC controller based on internal model control structure used the least square method and applied for both cases of static controller gain and adaptive controller gain. In [16], a novel fuzzy controller with a filtered derivative exploit and fractional order integrator was suggested and developed to resolve an automatic generation control problem in an interconnected multi-area power network. The study of intelligent control for LFC was used in an extended classifier system with constant-valued inputs to modify traditional frequency model [17]. The above methods contained the important results to resolve and build LFC problem in power systems. Unfortunately, some limitations of these controller methods are too complicated and of high order and requirement for on-line parameters identification implies for power system.

Among these presented control approaches, the SMC is attractive and powerful due to its ability to quickly converge, is useful to implement in power systems and is robust to external disturbances, system parameter variations and insensitivity with model errors of system. The SMC approach mainly include two steps: the selection of the sliding mode surface, and the design of the sliding mode controller. SMC has been used to solve the LFC problems of power networks with load disturbances 
and parameter uncertainties [18-30]. It is also perhaps insensitive to changes in the plant parameters and as well as improving system performance of transient control. In [18] was presented by another direction of a distributed sliding mode control approach for optimal LFC to control and regulate the system frequency and minimize the costs of power generation in power networks. The adaptive SMC problem of nonlinear Markovian jump systems was proposed in [19] to investigate and build in assuring the stochastic stability of power network. The design of a sliding-mode perturbation observer-based SMC was introduced and designed to enhance the stability of interconnected multi-area power networks in [20]. The proposed approach for LFC was presented and developed by a nonlinear SMC with matched and mismatched uncertainties, and it was applied to test in three control area power systems [21]. The non-linear SMC for LFC approach in [22,23] is robust and powerful in its ability to upgrade the performance of dynamic system. In [24,25], a method design is applied for power systems of LFC based on SOISMC theory and disturbance uncertainties observer to improve the stability of power system. The generalized extended state observer based on first-order SMC control was developed for a multi-area power network where parameter uncertainties were not considered [31].

In [32], the full order SMC was proposed to design an LFC scheme for a two-area power system, which is achieved when all the parameters of power system are at nominal values. The parameter uncertainties were not highlighted in an adaptive SMC method [33]. The LFC problems in power networks can be solved by the above approaches using SMC technique. However, the sliding mode load frequency controller given in [18-25] and [31-33] suffer from a major limitation known as the chattering phenomenon because of the discontinuous control signal used in the SMC. Such chattering has many negative effects in LFC in control areas of a power system since it may damage the control actuator and excite the undesirable unmodeled dynamics, which probably leads to a degradation and/or instability in system performance.

In this article, a continuous SMC strategy based on a SOISMC approach is introduced and developed for LFC of an interconnected multi-area power network. The major contributions of this research are the following:

- The second-order sliding mode controller based on integral sliding surface is offered to ensure the shortening of the frequency's transient response to avoid the overshoot.

- The performance of the power system is improved in the sense of reducing the chattering in comparison with the same SMC technique without using continuous controller. Therefore, the limitation of the first-order sliding mode control approach given in $[26,33]$ has been solved.

- A new LMI technique is derived to guarantee the stability of whole system via Lyapunov theory.

- The simulation results show and clearly prove the usefulness, the effectiveness and the robustness of the proposed second order SMC approach against the various disturbances such as matched, mismatched uncertainties and load variations. In comparison, the performance of the proposed SOISMC is better than the previous control by using differential games method given in [10].

The remain parts of this paper are presented in the following. A mathematical model of a multi-area interconnected power network is indicated in Section 2. The following proposed new second-order sliding mode load frequency control design is shown in Section 3. The discussion and simulation results are implied to evaluate the new second-order sliding mode control approach in Section 4. Lastly, the conclusion is discussed in Section 5.

\section{Mathematical Model of an Interconnected Multi-Area Power Network}

In this section, we first consider introducing a mathematical model or the dynamic model of the power network, and then analyzing the problem formulation of power systems. In studies, we realize that a multi-area power network is not only complicated but also nonlinear in a dynamic system with the parametric uncertainties and load variations. During the normal operation of power networks, the slow changes of load and resource appear in power system. That is a reason why we can linearize the dynamic model of power system around the point of normal system operation [26-30]. 
The proposed control law of LFC is designed for interconnected multi-area power network, which is presented in Figure 1 [26-30]:

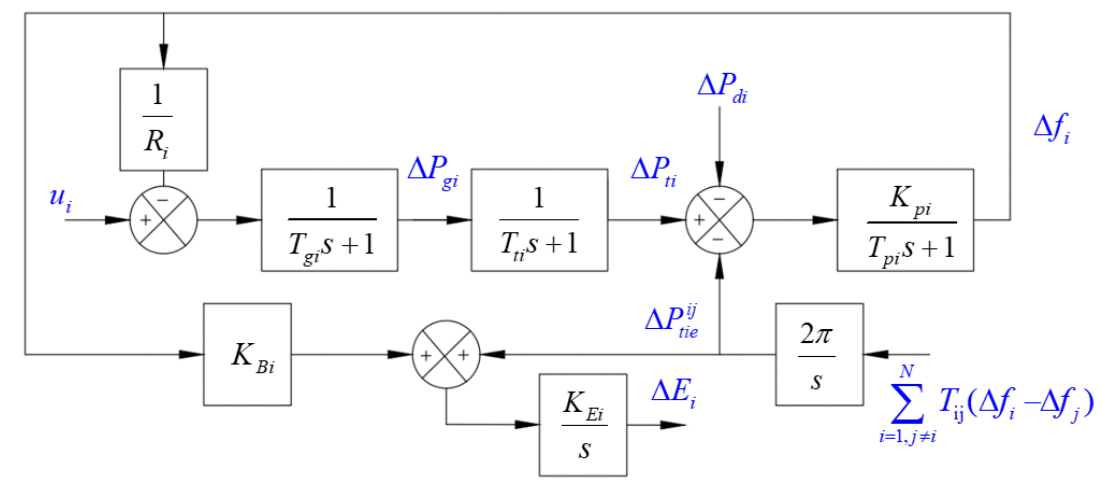

Figure 1. The simple block chart of the $i$ th area of a multi-area power network.

The frequency dynamic behavior of $i$ th area details in this section can be used in the following differential equation:

$$
\begin{gathered}
\Delta \dot{f}_{i}(t)=-\frac{1}{T_{p i}} \Delta f_{i}(t)+\frac{K_{p i}}{T_{p i}} \Delta P_{t i}(t)-\frac{K_{p i}}{T_{p i}} \Delta P_{d i}(t)-\frac{K_{p i}}{T_{p i}} \Delta P_{t i e}^{i j}(t) \\
\Delta \dot{P}_{t i}(t)=-\frac{1}{T_{t i}} \Delta P_{t i}(t)+\frac{1}{T_{t i}} \Delta P_{g i}(t) \\
\Delta \dot{P}_{g i}(t)=-\frac{1}{R_{i} T_{g i}} \Delta f_{i}(t)-\frac{1}{T_{g i}} \Delta P_{g_{i}}(t)+\frac{1}{T_{g i}} u_{i}(t) \\
\Delta \dot{E}_{i}=K_{B i} K_{E i} \Delta f_{i}+K_{E i} \Delta P_{t i e}^{i j} \\
\Delta \dot{P}_{t i e}^{i j}=\sum_{j=1}^{N} 2 \pi T_{i j}\left[\Delta f_{i}(t)-\Delta f_{j}(t)\right] \\
j \neq i
\end{gathered}
$$

where $i=1$ to $N$ and $N$ is defined the number of control areas, $\Delta f_{i}(t)$ and $\Delta f_{j}(t)$ are incremental changes in frequency of each control area, $\Delta P_{t i}(t)$ is incremental change in governor output command, $\Delta P_{g i}(t)$ is incremental change in governor valve position of each area, $\Delta P_{t i e}^{i j}(t)$ is total tie line power change between control $i$ th area and all other control areas, $\Delta P_{d i}(t)$ is incremental change in local load of each area, $\frac{1}{K_{p i}}=D_{i}$ is equivalent system damping coefficient of control area, $\frac{T_{p i}}{K_{p i}}=M_{i}$ is equivalent inertia constant of control area, $T_{i j}$ is tie-line power coefficient between $i$ th area and $j$ th area. $T_{g i}$ is time constants of governor, $T_{t i}$ is steam turbine time constant, $T_{p i}$ is power system time constant, respectively. $K_{p i}, R_{i}, K_{E i}, K_{B i}$ are power system gain, droop coefficient of individual area, speed regulation coefficient and frequency bias factor. Therefore, the state space modeling of $i$ th area of the matrix form showing in the dynamic equations from (1) to (5) is given by (6):

$$
\dot{x}_{i}(t)=A_{i} x_{i}(t)+B_{i} u_{i}(t)+\sum_{\substack{j=1 \\ j \neq i}}^{N} H_{i j} x_{j}(t)+F_{i} \Delta P_{d i}(t)
$$

where,

$$
x_{i}(t)=\left[\begin{array}{lllll}
\Delta f_{i}(t) & \Delta P_{t i}(t) & \Delta P_{g i}(t) & \Delta E_{i}(t) & \Delta P_{t i e}^{i j}(t)
\end{array}\right]^{T}
$$




$$
\begin{gathered}
A_{i}=\left[\begin{array}{ccccc}
-\frac{1}{T_{p i}} & \frac{K_{p i}}{T_{p i}} & 0 & 0 & -\frac{K_{p i}}{T_{p i}} \\
0 & -\frac{1}{T_{t i}} & \frac{1}{T_{t i}} & 0 & 0 \\
-\frac{1}{R_{i} T_{p i}} & 0 & -\frac{1}{T_{g i}} & 0 & 0 \\
K_{B i} K_{E i} & 0 & 0 & 0 & K_{E i} \\
\sum_{j=1}^{N} 2 \pi T_{i j} & 0 & 0 & 0 & 0 \\
j \neq i &
\end{array}\right], H_{i j}=\left[\begin{array}{rrrrr}
0 & 0 & 0 & 0 \\
0 & 0 & 0 & 0 \\
0 & 0 & 0 & 0 \\
0 & 0 & 0 & 0 & 0 \\
0 & \\
\sum_{j=1}^{N} 2 \pi T_{i j} & 0 & 0 & 0 & 0 \\
j \neq i &
\end{array}\right] \\
B_{i}=\left[\begin{array}{lllll}
0 & 0 & \frac{1}{T_{g i}} & 0 & 0
\end{array}\right]^{T}, F_{i}=\left[\begin{array}{lllll}
-\frac{K_{p i}}{T_{p i}} & 0 & 0 & 0 & 0
\end{array}\right]^{T}
\end{gathered}
$$

and $x_{i}(t) \in R^{n_{i}}$ is the state vector, $x_{j}(t) \in R^{n_{j}}$ is the neighboring state vector of $x_{i}(t), u_{i}(t) \in R^{m_{i}}$ is the control vector, $A_{i} \in R^{n_{i} \times n_{i}}, B_{i} \in R^{n_{i} \times m_{i}}, F_{i} \in R^{n_{i} \times k_{i}}$ are matrices of the nominal parameters, $n_{i}$ is the number of state variables of $i$ th area, $m_{i}$ is the number of control input variables of $i$ th area.

In a practical power network, the operation point varies constantly and is induced by load disturbance and fluctuating resources. Considering the uncertainties and parameter variations, the power system model can also be described as

$$
\begin{aligned}
\dot{x}_{i}(t) & =\left[A_{i}+\Theta_{i}\left(x_{i}, t\right)\right] x_{i}(t)+B_{i}\left[u_{i}(t)+\xi_{i}\left(x_{i}, t\right)\right] \\
+ & \sum_{\substack{j=1 \\
j \neq i}}^{N}\left[H_{i j}+\Xi_{i j}\left(x_{j}, t\right)\right] x_{j}(t)+F_{i} \Delta P_{d i}(t)
\end{aligned}
$$

where $\Theta_{i}\left(x_{i}, t\right)$ is time varying parameter uncertainties in the state matrix, $\Xi_{i j}\left(x_{j}, t\right)$ is time varying parameter uncertainties in the interconnected matrix and $\xi_{i}\left(x_{i}, t\right)$ is the disturbance input. Furthermore, we can call the aggregated uncertainties and the number of areas is 1 to $N$ :

$$
L_{i}\left(x_{i}, t\right)=\Theta_{i}\left(x_{i}, t\right) x_{i}(t)+B_{i} \xi_{i}\left(x_{i}, t\right)+\sum_{\substack{j=1 \\ j \neq i}}^{N} \Xi_{i j}\left(x_{j}, t\right) x_{j}(t)+F_{i} \Delta P_{d i}(t)
$$

So, the dynamic model (6) can also be presented by:

$$
\dot{x}_{i}(t)=A_{i} x_{i}(t)+B_{i} u_{i}(t)+\sum_{\substack{j=1 \\ j \neq i}}^{N} H_{i j} x_{j}(t)+L_{i}\left(x_{i}, t\right)
$$

where the aggregated disturbance $L_{i}\left(x_{i}, t\right)$ represents the uncertainties with the matched part and mismatched part.

Assumption 1. It is assumed that aggregateddisturbance $L_{i}\left(x_{i}, t\right)$ and the differential of $L_{i}\left(x_{i}, t\right)$ arebounded,i.e., there exist known scalars $\gamma_{i}$ and $\bar{\gamma}_{i}$ such that $\left\|L_{i}\left(x_{i}, t\right)\right\| \leq \gamma_{i}$ and $\left\|\dot{L}_{i}\left(x_{i}, t\right)\right\| \leq \bar{\gamma}_{i}$, where $\|$.$\| is the matrix norm.$

In order to prove the stability, we recall the lemma as below:

Lemma 1. [34]. Let $\mathbf{X}$ and $\mathbf{Y}$ are actual matrices with appropriate dimension then, for any scalar $\mu>0$, the sequent matrix inequality obtains

$$
\mathbf{X}^{\mathrm{T}} \mathbf{Y}+\mathbf{Y}^{\mathrm{T}} \mathbf{X} \leq \mu \mathbf{X}^{\mathrm{T}} \mathbf{X}+\mu^{-1} \mathbf{Y}^{\mathrm{T}} \mathbf{Y}
$$




\section{A New Second Order Sliding Mode Load Frequency Control Design}

In this section, a new SOISMC method is suggested and developed for power networks with parametric uncertainties and disturbances. To solve this problem, we work step-by-step to design and implement the new proposed controller approach. Firstly, the integral sliding surface is represented for the multi-area power system to assure that whole power networks are asymptotically stable. Secondly, the second-order SMC law design based on Lyapunov stability theorem is introduced to prove that the system states reach the sliding manifold, and the system states stay on the sliding manifold thereafter under external disturbances and internal parameter uncertainties.

\subsection{Stability Analysis of the Multi-Area Power Network in Sliding Mode Dynamics}

In detail, we first begin to propose and build an integral sliding surface for an interconnected multi-area power network (9)

$$
\sigma_{i}\left[x_{i}(t)\right]=G_{i} x_{i}(t)-\int_{0}^{t} G_{i}\left(A_{i}-B_{i} K_{i}\right) x_{i}(\tau) d \tau
$$

where $G_{i}$ is constant matrix and $K_{i}$ is the design matrix, matrix $G_{i}$ is chosen to guarantee that matrix $G_{i} B_{i}$ is nonsingular. The design matrix $K_{i} \in R^{m_{i} \times n_{i}}$ is selected to satisfy the inequality condition of the power system.

$$
\operatorname{Re}\left[\lambda_{\max }\left(A_{i}-B_{i} K_{i}\right)\right]<0
$$

If we recognize and differentiate $\sigma_{i}\left[x_{i}(t)\right]$ with respect to time combined with (9), then

$$
\dot{\sigma}_{i}\left[x_{i}(t)\right]=G_{i}\left[A_{i} x_{i}(t)+B_{i} u_{i}(t)+\sum_{\substack{j=1 \\ j \neq i}}^{N} H_{i j} x_{j}(t)+L_{i}\left(x_{i}, t\right)-G_{i}\left(A_{i}-B_{i} K_{i}\right) x_{i}(t)\right]
$$

So, the setting $\sigma_{i}\left[x_{i}(t)\right]=\dot{\sigma}_{i}\left[x_{i}(t)\right]=0$, the equivalent control is rewritten by

$$
u_{i}^{e q}(t)=-\left(G_{i} B_{i}\right)^{-1}\left[G_{i} A_{i} x_{i}(t)+\sum_{\substack{j=1 \\ j \neq i}}^{N} G_{i} H_{i j} x_{j}(t)+G_{i} L_{i}\left(x_{i}, t\right)-G_{i}\left(A_{i}-B_{i} K_{i}\right) x_{i}(t)\right]
$$

Substituting $u_{i}(t)$ with $u_{i}^{e q}(t)$ into the power systems (9) yields the sliding motion.

$$
\dot{x}_{i}(t)=\left(A_{i}-B_{i} K_{i}\right) x_{i}(t)+\left[I_{i}-B_{i}\left(G_{i} B_{i}\right)^{-1} G_{i}\right] L_{i}\left(x_{i}, t\right)+\sum_{\substack{j=1 \\ j \neq i}}^{N}\left[I_{i}-B_{i}\left(G_{i} B_{i}\right)^{-1} G_{i}\right] H_{i j} x_{j}(t)
$$

The following theorem makes a condition that the second-order sliding mode dynamic Equation (13) is asymptotically stable. 
Theorem 1. The sliding motion (15) is asymptotically stable if and only if there includes symmetric positive definite matrix $P_{i}, i=1,2, \ldots, N$, and positive scalars $\hat{\varepsilon}_{i}$ and $\alpha_{j}$ such that the following LMIs obtains

$$
\left[\begin{array}{cc}
\left(A_{i}-B_{i} K_{i}\right)^{T} P_{i}+P_{i}\left(A_{i}-B_{i} K_{i}\right)+\sum_{\substack{j=1 \\
j \neq i}}^{N} \alpha_{j}^{-1} H_{j i}^{T} H_{j i} & P_{i}\left[I_{i}-B_{i}\left(G_{i} B_{i}\right)^{-1} G_{i}\right] \\
{\left[I_{i}-B_{i}\left(G_{i} B_{i}\right)^{-1} G_{i}\right]^{T} P_{i}} & -\hat{\varepsilon}_{i}^{-1}
\end{array}\right]<0
$$

Proof 1. To study and analyze stability of the sliding motion (15), we choose the Lyapunov function as follows:

$$
V=\sum_{i}^{N} x_{i}^{T}(t) P_{i} x_{i}(t)
$$

where $P_{i}>0$ satisfies (17) Then, taking the time derivative of (17) and using Equation (15), we have

$$
\begin{aligned}
& \dot{V}=\sum_{i=1}^{N} \dot{x}_{i}^{T}(t) P_{i} x_{i}(t)+x_{i}^{T}(t) P_{i} \dot{x}_{i}(t) \\
& =\sum_{i=1}^{N}\left\{x_{i}^{T}(t)\left[\left(A_{i}-B_{i} K_{i}\right)^{T} P_{i}+P_{i}\left(A_{i}-B_{i} K_{i}\right)\right] x_{i}(t)+\sum_{\substack{j=1 \\
j \neq i}}^{N} x_{j}^{T}(t) H_{i j}^{T}\left[I_{i}-B_{i}\left(G_{i} B_{i}\right)^{-1} G_{i}\right]^{T} P_{i} x_{i}(t)\right. \\
& +\sum_{\substack{j=1 \\
j \neq i}}^{N} x_{i}^{T}(t) P_{i}\left[I_{i}-B_{i}\left(G_{i} B_{i}\right)^{-1} G_{i}\right] H_{i j} x_{j}(t)+x_{i}^{T}(t) P_{i}\left[I_{i}-B_{i}\left(G_{i} B_{i}\right)^{-1} G_{i}\right] L_{i}\left(x_{i}, t\right) \\
& \left.+L_{i}^{T}\left(x_{i}, t\right)\left[I_{i}-B_{i}\left(G_{i} B_{i}\right)^{-1} G_{i}\right] T P_{i} x_{i}(t)\right\}
\end{aligned}
$$

Applying Lemma 1 to Equation (18), we have:

$$
\begin{aligned}
& \dot{V} \leq \sum_{i=1}^{N}\left\{x_{i}^{T}(t)\left[\left(A_{i}-B_{i} K_{i}\right)^{T} P_{i}+P_{i}\left(A_{i}-B_{i} K_{i}\right)\right] x_{i}(t) \sum_{\substack{j=1 \\
j \neq i}}^{N} x_{i}^{T}(t) \alpha_{i}^{-1} H_{i j}^{T} H_{i j} x_{j}\right. \\
& +\sum_{\substack{j=1 \\
j \neq i}}^{N} x_{i}^{T}(t) \alpha_{i} P_{i}\left[I_{i}-B_{i}\left(G_{i} B_{i}\right)^{-1} G_{i}\right]\left[I_{i}-B_{i}\left(G_{i} B_{i}\right)^{-1} G_{i}\right]^{T} P_{i} x_{i}(t) \\
& \left.+x_{i}^{T}(t) \beta_{i} P_{i}\left[I_{i}-B_{i}\left(G_{i} B_{i}\right)^{-1} G_{i}\right]\left[I_{i}-B_{i}\left(G_{i} B_{i}\right)^{-1} G_{i}\right]^{T} P_{i} x_{i}(t)+\beta_{i}^{-1} L_{i}^{T}\left(x_{i}, t\right) L_{i}\left(x_{i}, t\right)\right\}
\end{aligned}
$$

Since $\sum_{i=1}^{N} \sum_{\substack{j=1 \\ j \neq i}}^{N} x_{j}^{T}(t) \alpha_{i}^{-1} H_{i j}^{T} H_{i j} x_{j}(t)=\sum_{i=1}^{N} \sum_{\substack{j=1 \\ j \neq i}}^{N} x_{i}^{T}(t) \alpha_{j}^{-1} H_{j i}^{T} H_{j i} x_{i}(t)$ we achieve that:

$$
\begin{aligned}
\dot{V} & \leq \sum_{i=1}^{N}\left\{x _ { i } ^ { T } ( t ) \left[\left(A_{i}-B_{i} K_{i}\right)^{T} P_{i}+P_{i}\left(A_{i}-B_{i} K_{i}\right)+\hat{\varepsilon}_{i} P_{i}\left[I_{i}-B_{i}\left(G_{i} B_{i}\right)^{-1} G_{i}\right]\left[I_{i}-B_{i}\left(G_{i} B_{i}\right)^{-1} G_{i}\right]^{T} P_{i}\right.\right. \\
& \left.+\sum_{\substack{j=1 \\
j \neq i}}^{N} \alpha_{j}^{-1} H_{j i}^{T} H_{j i}\right] x_{i}(t)+\sum_{i=1}^{N} \mu_{i}
\end{aligned}
$$


where $\hat{\varepsilon}_{i}=\alpha_{i}(N-1)+\beta_{i}$ and $\mu_{i}=\beta_{i}^{-1} \gamma_{i}^{2}$. In addition, by the Schur complement of [35], LMIs (20) is equivalent to this inequality:

$$
\left(A_{i}-B_{i} K_{i}\right)^{T} P_{i}+P_{i}\left(A_{i}-B_{i} K_{i}\right)+\varepsilon_{i} P_{i}\left[I_{i}-B_{i}\left(G_{i} B_{i}\right)^{-1} G_{i}\right]\left[I_{i}-B_{i}\left(G_{i} B_{i}\right)^{-1} G_{i}\right]^{T} P_{i}+\sum_{\substack{j=1 \\ j \neq i}}^{N} \alpha_{j}^{-1} H_{j i}^{T} H_{j i}=-\Omega_{i}<0
$$

According to Equations (20) and (21), we obtain

$$
\dot{V} \leq \sum_{i=1}^{N}\left[-\lambda_{\min }\left(\Omega_{i}\right)\left\|x_{i}(t)\right\|^{2}+\mu_{i}\right]
$$

where the constant value $\mu_{i}$ and the eigenvalue $\lambda_{\min }\left(\Omega_{i}\right)>0$. Therefore, $\dot{V}<0$ is achieved with $\left\|x_{i}(t)\right\|>\sqrt{\frac{\mu_{i}}{\lambda_{\min }\left(\Omega_{i}\right)}}$. Hence, the sliding motion of system (15) is asymptotically stable.

\subsection{Load Frequency Controller Design}

In the previous step, we introduce and prove that power networks with an integral sliding surface (ISS) work to be asymptotically stable and smooth in the sliding mode under assured conditions. In the next step, a new SOISMC scheme is presented for the multi-area interconnected power network to eliminate chattering and oscillating in the ISS. The main purpose of proposed control scheme is to effect on the second order derivative of the sliding variables $\sigma_{i}\left[x_{i}(t)\right]$. By using the discontinuous control signal $\dot{u}_{i}(t)$, it is simple to make $\sigma_{i}\left[x_{i}(t)\right]$ and $\dot{\sigma}_{i}\left[x_{i}(t)\right]$ converge to zero. So, the input control signal $u_{i}(t)$ of power systems can be obtained by integrating the discontinuous signal $\dot{u}_{i}(t)$ to make continuous signal $u_{i}(t)$. Therefore, the second-order SMC approach removes some undesired frequency oscillations in the control signal of power system.

We define and establish the sliding manifold $S_{i}\left[x_{i}(t)\right]$ as

$$
S_{i}\left[x_{i}(t)\right]=\dot{\sigma}_{i}\left[x_{i}(t)\right]+\delta_{i} \sigma_{i}\left[x_{i}(t)\right]
$$

and

$$
\dot{S}_{i}\left[x_{i}(t)\right]=\ddot{\sigma}_{i}\left[x_{i}(t)\right]+\delta_{i} \dot{\sigma}_{i}\left[x_{i}(t)\right]
$$

where $\delta_{i}>0$ is a positive constant. According to Equation (9), the Equation (24) can be rewritten as

$$
\begin{gathered}
\dot{S}_{i}\left[x_{i}(t)\right]=G_{i}\left[A_{i} \dot{x}_{i}(t)+B_{i} \dot{u}_{i}(t)+\sum_{\substack{j=1 \\
j \neq i}}^{N} H_{i j} \dot{x}_{j}(t)+\dot{L}_{i}\left(x_{i}, t\right)\right] \\
-G_{i}\left(A_{i}-B_{i} K_{i}\right) \dot{x}_{i}(t)+\delta_{i} \dot{\sigma}_{i}\left[x_{i}(t)\right]
\end{gathered}
$$

Based on the definition of sliding surface and sliding manifold, the continuous decentralized second-order sliding mode LFC for power networks be given as follows:

$$
\dot{u}_{i}(t)=-\left(G_{i} B_{i}\right)^{-1}\left[\| G _ { i } \| \left\|B_{i}\left|\left\|\mid K_{i}\right\|\left\|\dot{x}_{i}(t)\right\|+\sum_{\substack{j=1 \\ j \neq i}}^{N}\left\|G_{j}\right\|\left\|H_{j i}\right\|\left\|\dot{x}_{i}(t)\right\|+\delta_{i}\left\|\dot{\sigma}_{i}\left[x_{i}(t)\right]\right\|+\left\|G_{i}\right\| \bar{\gamma}_{i}+\bar{\varepsilon}\right] \frac{S_{i}\left[x_{i}(t)\right]}{\left\|S_{i}\left(x_{i}(t)\right]\right\|}\right.\right.
$$

Then we have the following main results.

Theorem 2. Consider the closed loop of the power systems (15) with the continuous sliding mode controller (26). Then, every solution trajectory is directed towards the sliding manifold $S_{i}\left[x_{i}(t)\right]=0$ and once the trajectory hits the sliding manifold $S_{i}\left[x_{i}(t)\right]=0$ it remains on the sliding manifold thereafter. 
Proof 2. The Lyapunov function is introduced as below

$$
\bar{V}(t)=\sum_{i=1}^{N}\left\|S_{i}\left[x_{i}(t)\right]\right\|
$$

So, taking the derivative of $\bar{V}(t)$ that we have:

$$
\begin{gathered}
\dot{\bar{V}}=\sum_{i=1}^{N} \frac{S_{i}^{T}\left[x_{i}(t)\right]}{\left\|S_{i}\left[x_{i}(t)\right]\right\|} \dot{S}_{i}\left[x_{i}(t)\right] \\
=\sum_{i=1}^{N} \frac{S_{i}^{T}\left[x_{i}(t)\right]}{\left\|S_{i}\left[x_{i}(t)\right]\right\|}\left\{G_{i}\left[A_{i} \dot{x}_{i}(t)+B_{i} \dot{u}_{i}(t)+\sum_{\substack{j=1 \\
j \neq i}}^{N} H_{i j} \dot{x}_{j}(t)+\dot{L}_{i}\left(x_{i}, t\right)\right]\right. \\
\left.\quad-G_{i}\left(A_{i}-B_{i} K_{i}\right) \dot{x}_{i}(t)+\delta_{i} \dot{\sigma}_{i}\left[x_{i}(t)\right]\right\}
\end{gathered}
$$

According to Equation (24) and property $\|A B\| \leq\|A\|\|B\|$, it generates

$$
\begin{aligned}
\dot{\bar{V}}= & \sum_{i=1}^{N}\left\{G_{i} B_{i} K_{i} \dot{x}_{i}(t)+\delta_{i} \dot{\sigma}_{i}\left[x_{i}(t)\right]+\sum_{\substack{j=1 \\
j \neq i}}^{N} G_{i} H_{i j} \dot{x}_{j}(t)+G_{i} \dot{L}_{i}\left(x_{i}, t\right)\right\}+\sum_{i=1}^{N} \frac{S_{i}^{T}\left[x_{i}(t)\right]}{\left\|S_{i}\left[x_{i}(t)\right]\right\|} G_{i} B_{i} \dot{u}_{i}(t) \\
\leq & \sum_{i=1}^{N}\left\{\left\|G_{i}\right\|\left\|B_{i}\right\|\left\|K_{i}\right\|\left\|\dot{x}_{i}(t)\right\|+\delta_{i}\left\|\dot{\sigma}_{i}\left[x_{i}(t)\right]\right\|+\sum_{\substack{j=1 \\
j \neq i}}^{N}\left\|G_{i}\right\|\left\|H_{i j}\right\|\left\|\dot{x}_{j}(t)\right\|+\left\|G_{i}\right\|\left\|\dot{L}_{i}\left(x_{i}, t\right)\right\|\right\} \\
& +\sum_{i=1}^{N} \frac{S_{i}^{T}\left[x_{i}(t)\right]}{\left\|S_{i}\left[x_{i}(t)\right]\right\|} G_{i} B_{i} \dot{u}_{i}(t)
\end{aligned}
$$

Using Assumption 1 we achieve:

$$
\begin{aligned}
\dot{\bar{V}} & \leq \sum_{i=1}^{N}\left\{\left\|G_{i}\right\|\left\|B_{i}\right\|\left\|K_{i}\right\|\left\|\dot{x}_{i}(t)\right\|+\delta_{i}\left\|\dot{\sigma}_{i}\left[x_{i}(t)\right]\right\|+\left\|G_{i}\right\| \bar{\gamma}_{i}+\sum_{\substack{j=1 \\
j \neq i}}^{N}\left\|G_{j}\right\|\left\|H_{j i}\right\|\left\|\dot{x}_{i}(t)\right\|\right\} \\
& +\sum_{i=1}^{N} \frac{S_{i}^{T}\left[x_{i}(t)\right]}{\left\|S_{i}\left[x_{i}(t)\right]\right\|} G_{i} B_{i} \dot{u}_{i}(t)
\end{aligned}
$$

Using the control law (24) yields:

$$
\dot{\bar{V}} \leq-\sum_{i=1}^{N} \bar{\varepsilon}_{i}
$$

The above inequality implies that the state trajectories of the multi-area power system (8) reach the sliding manifold $S_{i}\left[x_{i}(t)\right]=0$ and stay on it thereafter.

\section{Simulation Results}

To analysis and evaluate the new SOISMC approach for LFC in the two-area power network, the system parameters were obtained in $[10,26,33]$. The reporting of simulation 1 , simulation 2 and simulation 3 are discussed with their different conditions in operation as follows:

\subsection{Simulation 1}

A typical two-area conventional power network is considered. The proposed controller is tested and analyzed in the system to explain the robustness and effectiveness as suggested for second order integral sliding mode controller. The parameters of both control areas in power systems were given in [10] as shown in Table 1. 
Table 1. The parameters of both control areas in power systems.

\begin{tabular}{ccccccc}
\hline Parameter & $T_{p i}[\mathrm{~s}]$ & $K_{p i}[\mathrm{~Hz} /$ p.u.MW $]$ & $T_{t i}[\mathrm{~s}]$ & $T_{g i}[\mathrm{~s}]$ & $\boldsymbol{R}_{i}[$ Hz/p.u.MW $]$ & $T_{12}[\mathrm{~Hz} /$ p.u.MW/rad $]$ \\
\hline $\begin{array}{c}\text { Value for } \\
\text { both areas }\end{array}$ & $20 \mathrm{~s}$ & 12 & 0.3 & 0.08 & 2.4 & 0.2545 \\
\hline
\end{tabular}

Case 1. At first, we assume that the system parameters are at nominal values. The load disturbances acting on the system are $\Delta P_{d 1}=0.01$ p.u. at $t_{1}=5 \mathrm{~s}$ in area 1 and $\Delta P_{d 2}=0.03$ p.u. at $t_{2}=3 \mathrm{~s}$ in area 2 of power system. The frequency deviation of both area $1 \Delta f_{1}$ and area $2 \Delta f_{2}$, tie-line power deviation $\Delta P_{\text {tie } 1}, \Delta P_{\text {tie } 2}$ and the control input of area $1 u_{1}$ and area $2 u_{2}$ are shown in Figures $2-4$. Additionally, the settling time for the frequency deviation to converge to zero is about $3 \mathrm{~s}$, which shows rapid response time to clear the disturbance as compared to 20-25 s response time given in [10]. It is easy to say that the proposed SOISMC creates a good dynamic response. Above all, the second-order law is used by the proposed controller to reduce overshoot and oscillation as well as the re-equipment of the system responses. The simulation results of Figures $2-4$ demonstrate the superiority of removing the chattering problem in finite frequency and verifying the usefulness of the proposed second-order integral sliding mode control law.

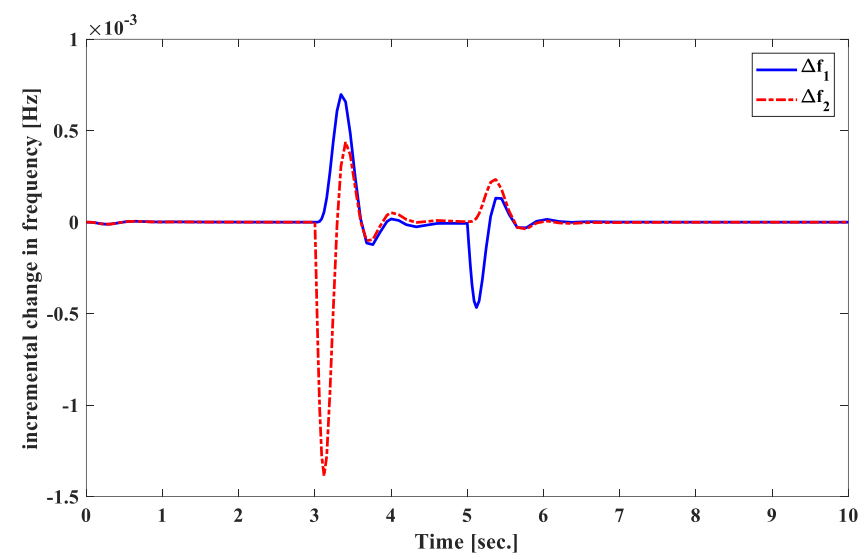

Figure 2. Frequency deviations $[\mathrm{Hz}]$ of the control areas 1 and 2 with matched disturbances.

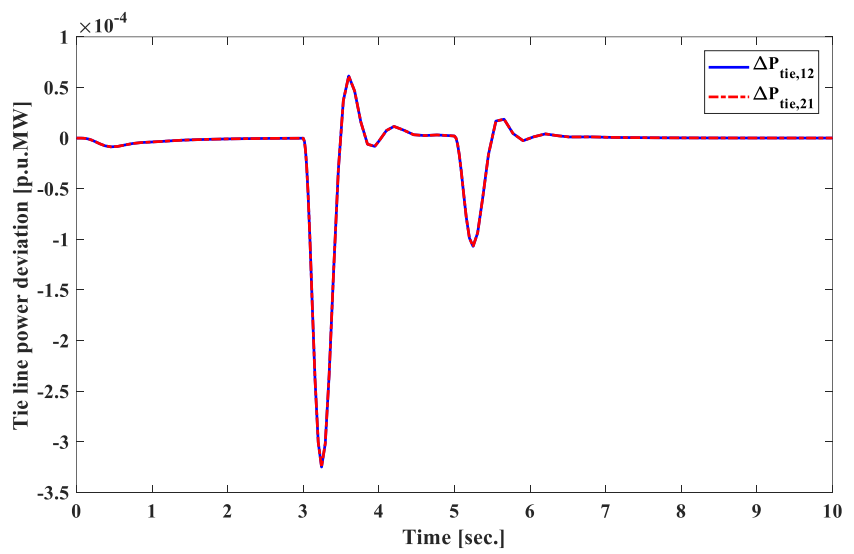

Figure 3. Tie line power deviation [p.u.MW] with matched disturbances. 


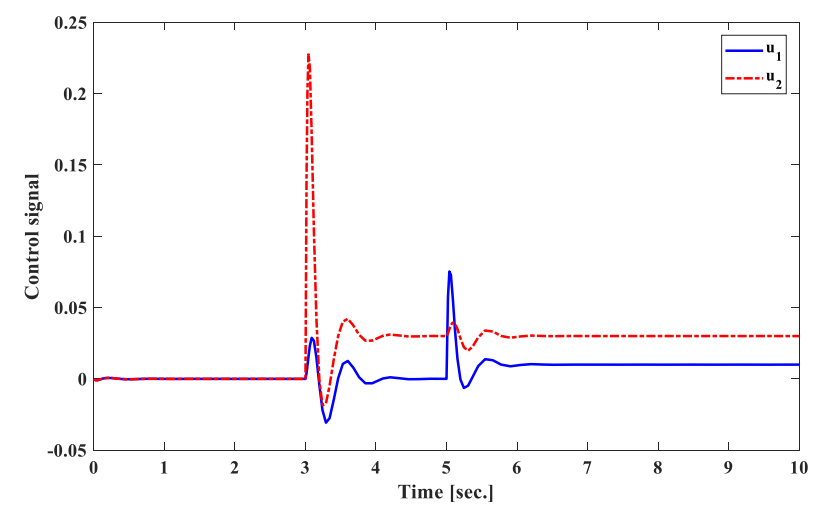

Figure 4. Control input [p.u.] of two control areas with matched disturbances.

Remark 1. The new proposed controller shows robustness and fast response against load disturbance better than previous approaches as seen in [10]. In detail, the load disturbance is clear, and the system is restored back to steady state at short settling time with smaller overshoots.

Case 2. To apply and carry out the proposed SOISMC scheme to the model of the power system in Figure 1, we consider the parameters of mismatched uncertainties in this case and the random load variations are used to test the suggested controller. To further validate the robustness of the proposed controller, random load disturbances show in Figure 5 and parameter nominal values with $\pm 20 \%$ deviation are introduced to the system. The results of Figure 6 show the proposed controller response to deviations in frequency of the first and second areas, respectively, while Figure 7 presents the tie-line power flow signal. Figure 8 displays the control signals in both areas.

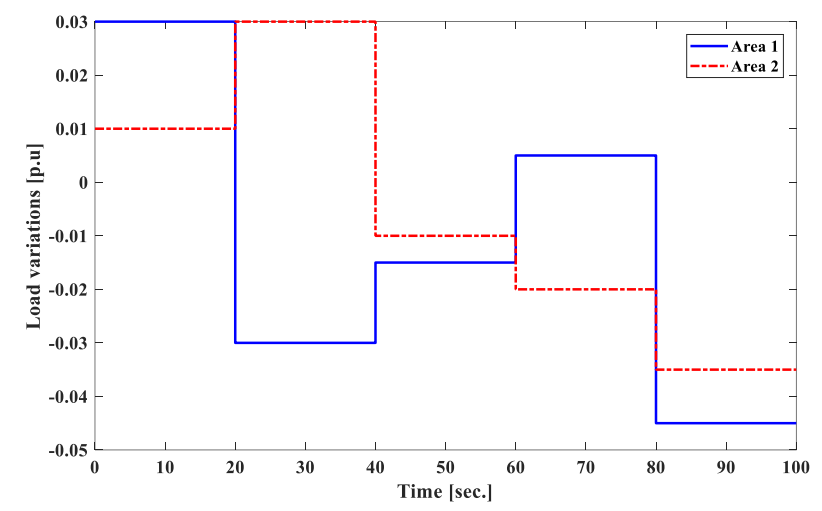

Figure 5. Variation load [p.u.] of areas 1 and 2 of the power system.

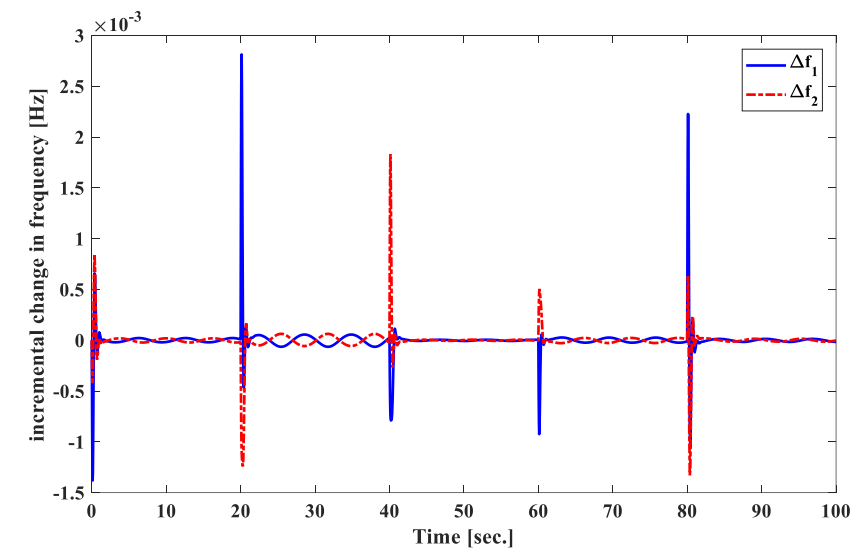

Figure 6. Frequency deviations $[\mathrm{Hz}]$ of the control areas 1 and 2 with matched disturbances. 


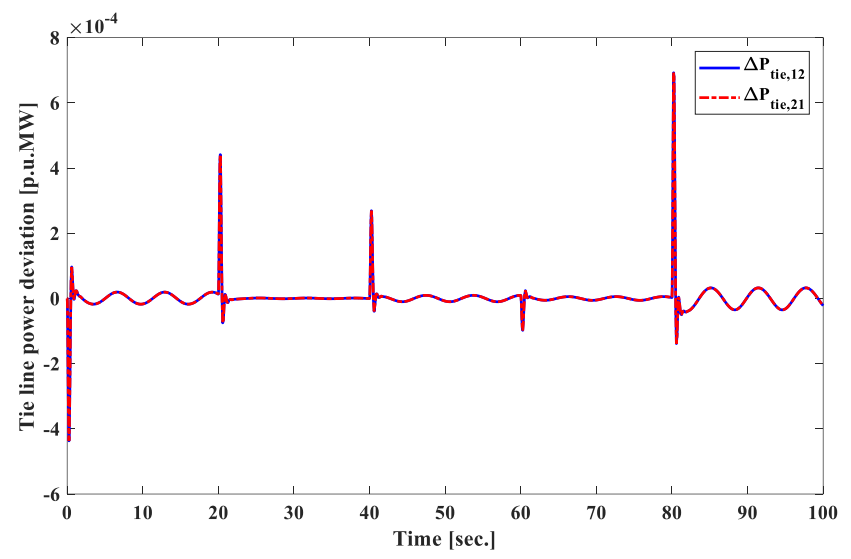

Figure 7. Tie line power deviation [p.u.MW] with matched disturbances.

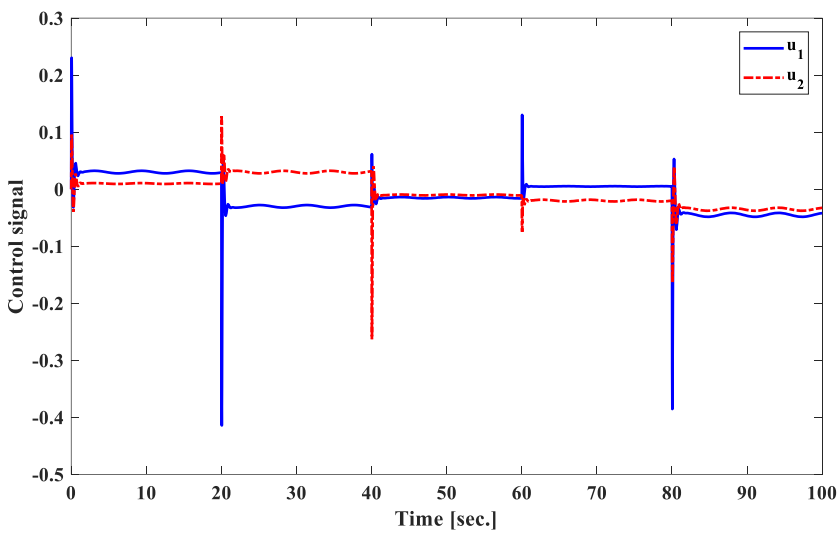

Figure 8. Control input [p.u.] of two control areas with matched disturbances.

\subsection{Simulation 2}

In this part, three cases are examined. The power system parameters of the two-area power network were given in [26] as shown Table 2.

Table 2. Parameters of load frequency control scheme.

\begin{tabular}{ccccccc}
\hline Parameter & $T_{p i}[\mathrm{~s}]$ & $K_{p i}[$ Hz/p.u.MW $]$ & $T_{t i}[\mathrm{~s}]$ & $T_{g i}[\mathrm{~s}]$ & {$[$ Hz/p.u.MW $]$} & $\boldsymbol{T}_{12}[\mathrm{~Hz} /$ p.u.MW/rad $]$ \\
\hline $\begin{array}{c}\text { Value for } \\
\text { both areas }\end{array}$ & 20 & 120 & 0.3 & 0.08 & 2.4 & 0.5450 \\
\hline
\end{tabular}

Case 1. To proceed, we again assume the system operate under nominal parameters. Load disturbances perturbing on the system are $\Delta P_{d 1}=0.01$ p.u at $t_{1}=1 \mathrm{~s}$ in area 1 and $\Delta P_{d 2}=0.02$ p.u. at $t_{2}=1 \mathrm{~s}$ in area 2 of power network. Figure 9 displays the signal of frequency deviation of control area 1 and 2 , at the time $t=1 \mathrm{~s}$, the step load disturbances in both areas is significantly increased, then the proposed controller receives the error signal of frequency from sensor and controls the frequency deviation to converge zero about $3 \mathrm{~s}$. The tie-line power flow signal of each area is also represented in Figure 10. Control signals of both areas are shown in Figure 11 without chattering and small control energy. So, a new scheme called SOISMC law has been showed in the simulation results from Figures 9-11 to indicate that the power system carries a good transient response to decrease and avoid the chattering problem. It is easy to conclude that the errors of frequency, errors of tie-line power and, even errors of control area can reach to zero at short time compared with previous control approach given in [26]. 


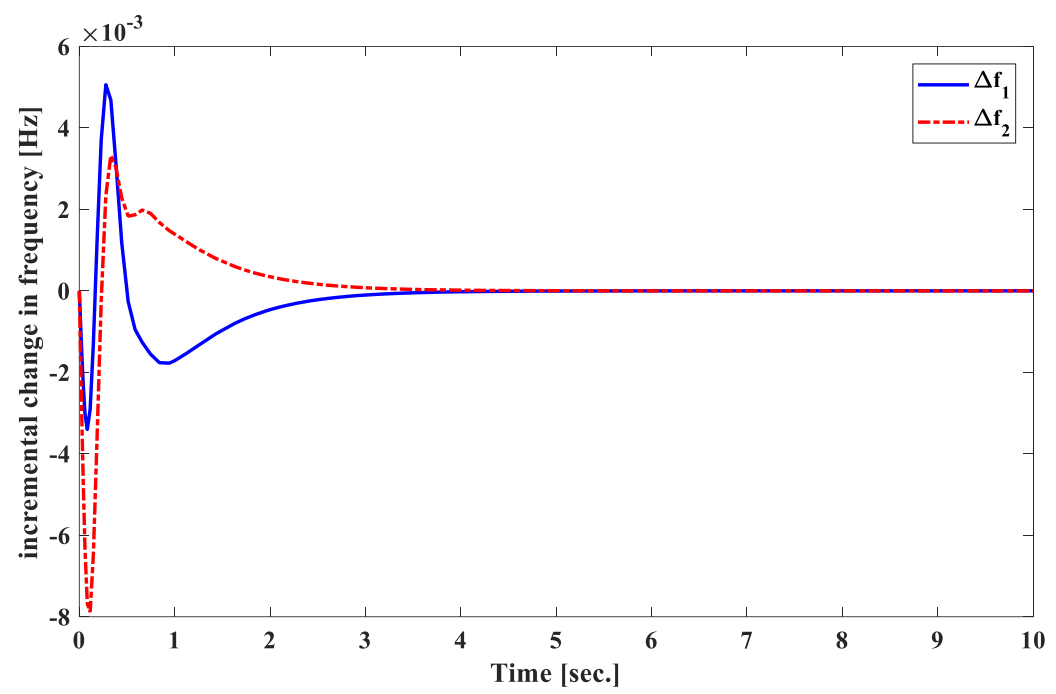

Figure 9. Frequency deviation $[\mathrm{Hz}]$ of control areas 1 and 2 with matched disturbances.

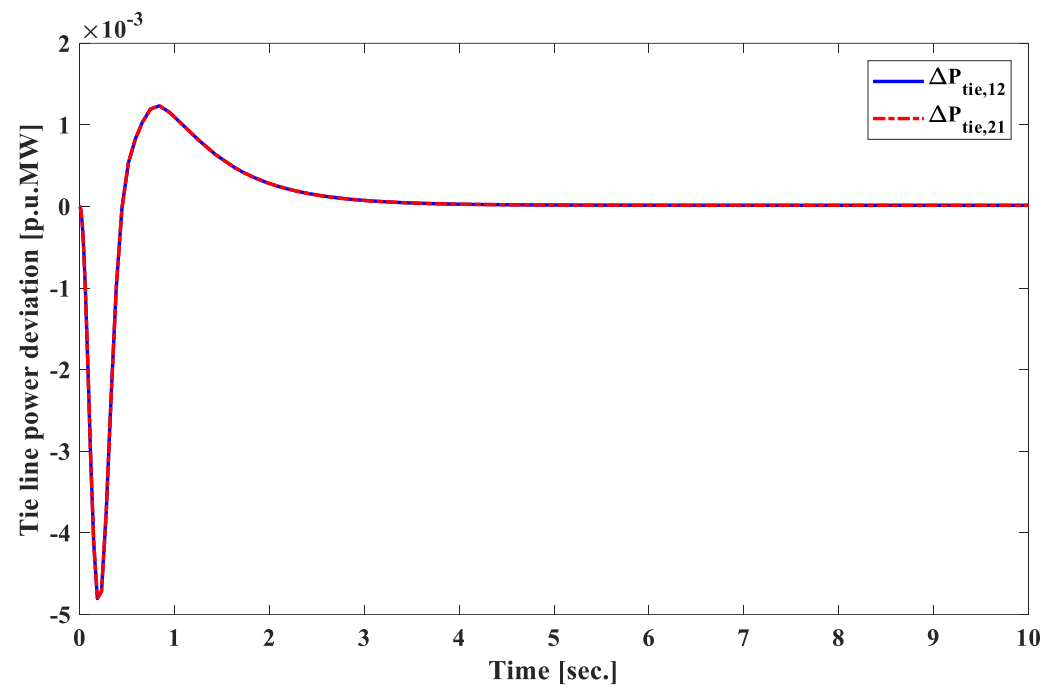

Figure 10. Tie-line power deviation [p.u.MW] of control areas 1 and 2 with matched disturbances.

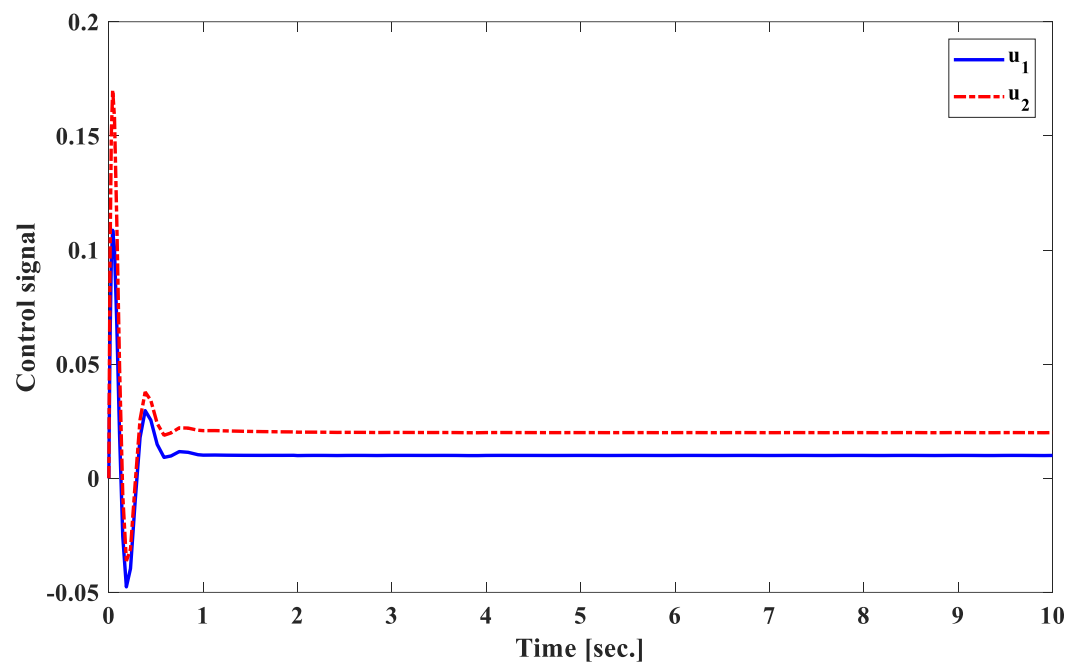

Figure 11. Control input [p.u.] of two control areas with matched disturbances. 
Case 2. In the previous cases, an interconnected multi-area power network works excellently under the parameters of matched and mismatched uncertainties. To analyze and investigate in different condition, $\pm 20 \%$ deviation of the nominal parameters is again assume and load disturbance $\Delta P_{d 1}=0.02$ p.u at $t_{1}=1 \mathrm{~s}$ in area 1 and the load disturbance $\Delta P_{d 2}=0.03$ p.u at $t_{2}=1 \mathrm{~s}$ in area 2 to implement and examine the powerful system response of the designed SOISMC approach.

In the second case, the system responses in the frequencies of generator and the changes of tie-line power to the load demand are considered to apply for the new approach. The results are shown in Figure 12 for frequency deviation, Figure 13 for tie-line power deviation, and Figure 14 for control input signal. Figure 12 presents the frequency deviate of generators to point out that the proposed second order approach helps the power system reach to ordinary value about 5-6s after load disturbances happen in the system. The scheduled value of tie-line power deviation is indicated in Figure 13. The comparative results between the suggested SOISMC approach and the previous method given in [26] show that the proposed method in Table 3 achieves a good transient response, such as smaller transient deviation and shorter settling time in terms of load disturbances.

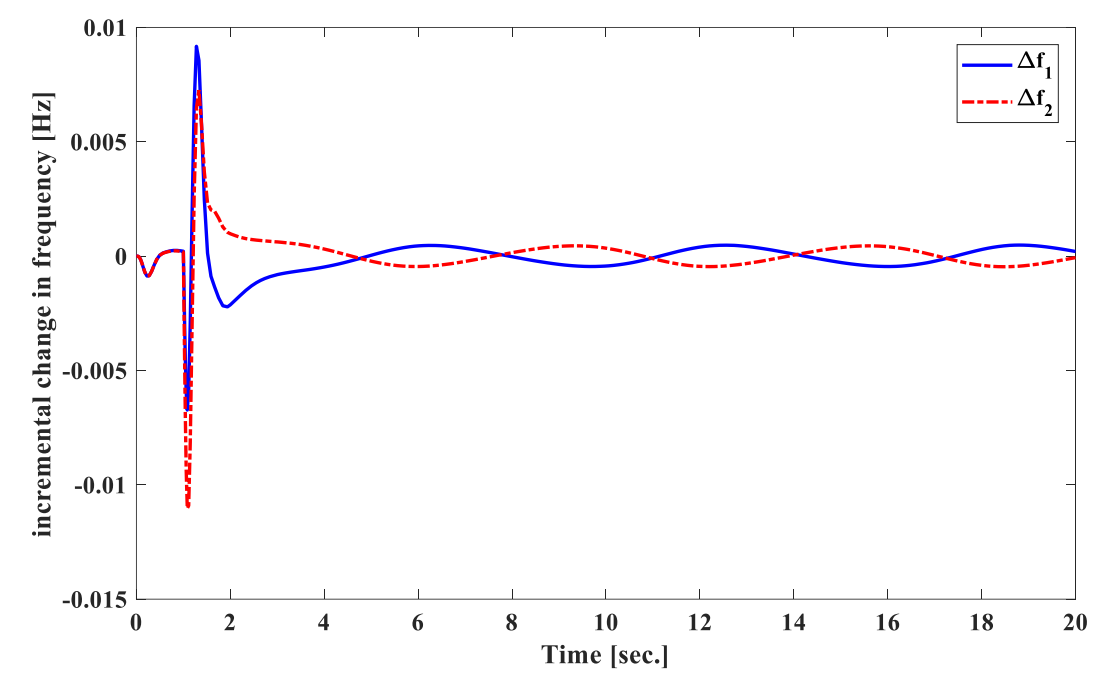

Figure 12. Frequency $[\mathrm{Hz}]$ of control area 1 and area 2 under mismatched disturbances.

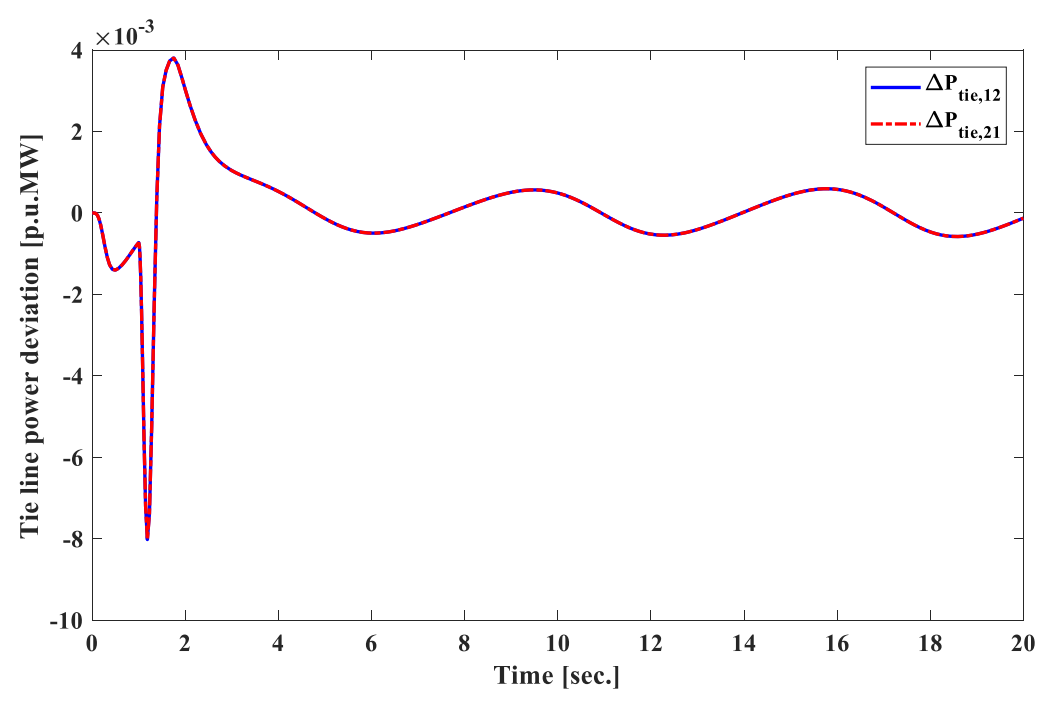

Figure 13. Tie-line power [p.u.MW] of control areas 1 and area 2 under mismatched disturbances. 


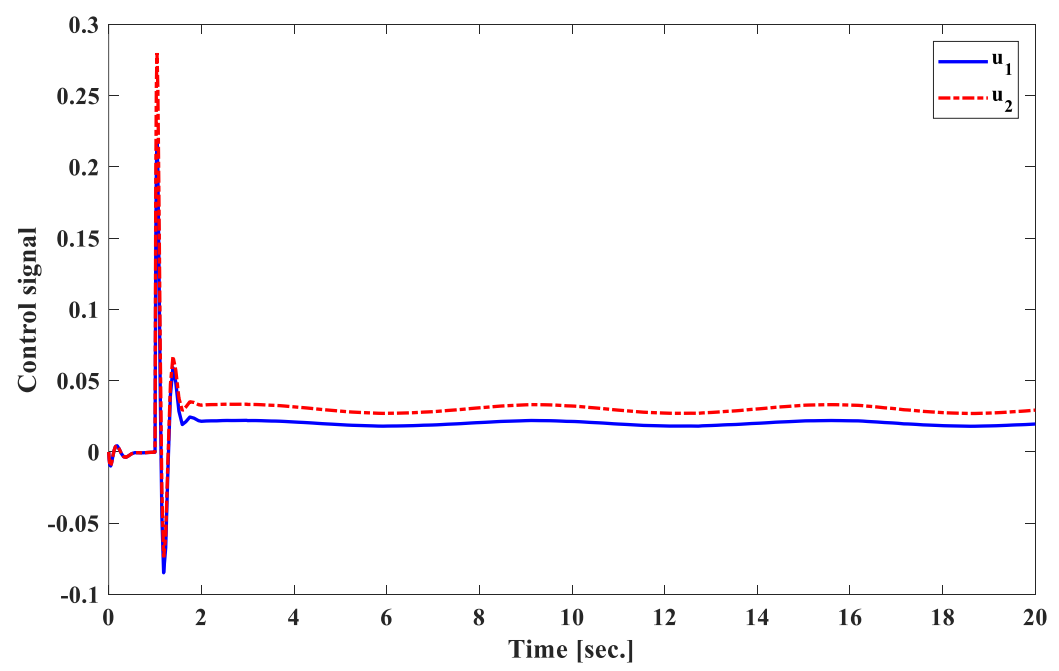

Figure 14. Control input [p.u.] of two control areas under mismatched disturbances.

Table 3. Setting time $T_{S}$ and Maximum over shoot calculation of SOISMC and different SMC method.

\begin{tabular}{ccccc}
\hline $\begin{array}{c}\text { Kinds of } \\
\text { Controller }\end{array}$ & \multicolumn{2}{c}{$\begin{array}{c}\text { The Proposed } \\
\text { SOISMC Approach }\end{array}$} & \multicolumn{2}{c}{$\begin{array}{c}\text { Different Sliding Mode } \\
\text { Control Scheme For LFC }\end{array}$} \\
\hline Parameters & $\boldsymbol{T}_{\boldsymbol{s}}[\mathbf{s}]$ & Max.O.S $[\mathbf{H z}]$ & $\boldsymbol{T}_{\boldsymbol{s}}[\mathbf{s}]$ & Max.O.S $[\mathbf{H z}]$ \\
\hline$\Delta f_{1}$ & 5 & 0.0090 & 105 & 0.0200 \\
$\Delta f_{2}$ & 6 & 0.0070 & 110 & 0.0150 \\
\hline
\end{tabular}

In the detailed analysis, it is simple to see in Figures 12 and 13 that the suggested control approach not only executes faster disturbance estimation but also makes a faster convergence rate and smaller oscillatory system response in chattering alleviation effect in comparison with the previous scheme in [26]. In both control areas, the incremental change in actual tie line power flow from control area-1 to 2 and control input effort are necessary to make the frequency droop down fast using proposed controller are shown in Figures 13 and 14. The incremental change in actual tie-line flow indicates inappreciable oscillatory transient response. Particularly, the proposed SOISMC controller enhances the characteristic of system damping. It was realized that the chattering effects are totally removed to deal to fact that the proposed second switching law is the principle of the effectiveness of the transient response. Thus, the proposed control approach performs well compared to [26] in the presence of the changed load disturbances.

Remark 2. This chattering problem in SMC is exceedingly damaging for actuators used in power systems. The proposed controller gives the correct signal and utilizes energy to compensate for frequency damping for main control consisting of governor. So that, the droop speed control of the governor will correctly actuate the valve to provide needed steam to the turbine to increase mechanical inertia power to match the load change or demand. Therefore, the setting time and overshoot are better in comparison with the proposed approach given in [26].

Remark 3. In this proposed approach, it is one of the most achievable objectives to finalize the mismatched disturbances and get shorter settling time and smaller transient deviation and lesser oscillation in terms of load disturbances for power system by the application of the second order control law. Therefore, some limitations of other control strategies in paper [26] have been resolved, such as reducing chattering effect and improving transient response.

Case 3. In the last case, we use and study load variations and the mismatched parameter uncertainties in the two-areas power system. We apply the random load to power networks under the same condition of case 2 . 
To prove the advantage of the proposed SOISMC approach, a random load variation is given in Figure 15 applied for two-area power networks. The simulation report displays from Figures 16-18 of the frequency deviations, tie-line power and control input signal to clearly present the performances of waveform for the different situations in the case of load variations and the mismatched parameter uncertainties. Therefore, that is a practical evidence of the suggested control scheme is powerful to limit and reduce the chattering phenomenon of power system. The other words, the suggested controller upgrades the characteristics of damping system. Consequently, the suggested controllers reach the nominal frequency and are reduced to zero in the exchange deviation of tie-line power with a good dynamic response of minimizing overshoots and shortening settling time comparing with the previous scheme in [26].

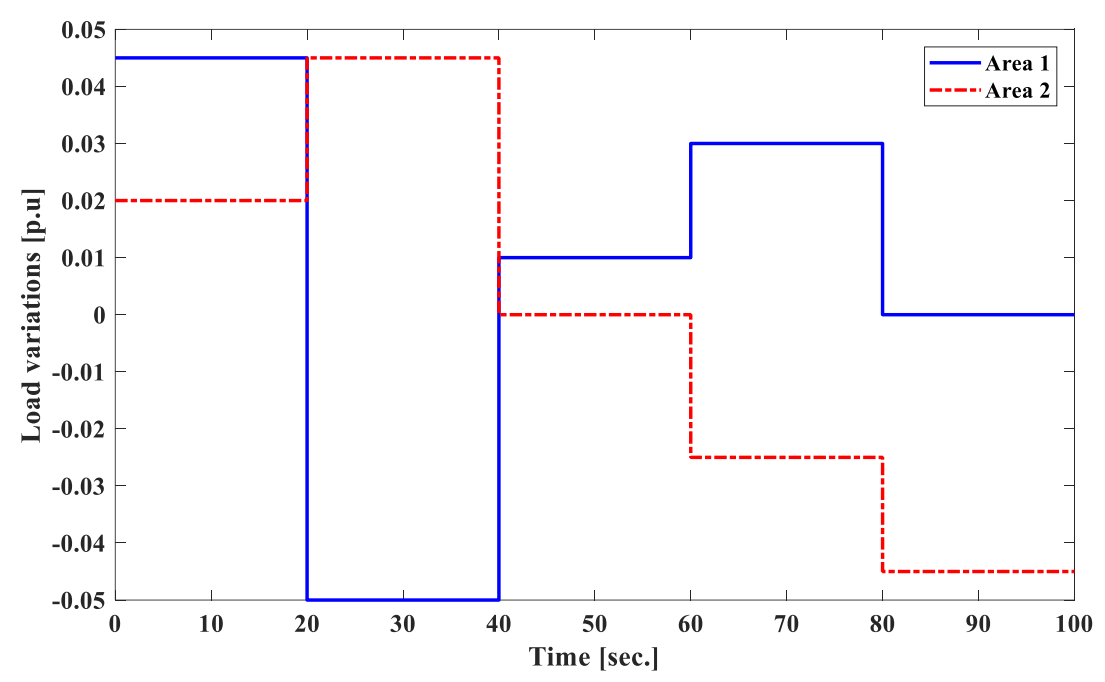

Figure 15. Variation load [p.u.] of areas 1 and 2 of the power system.

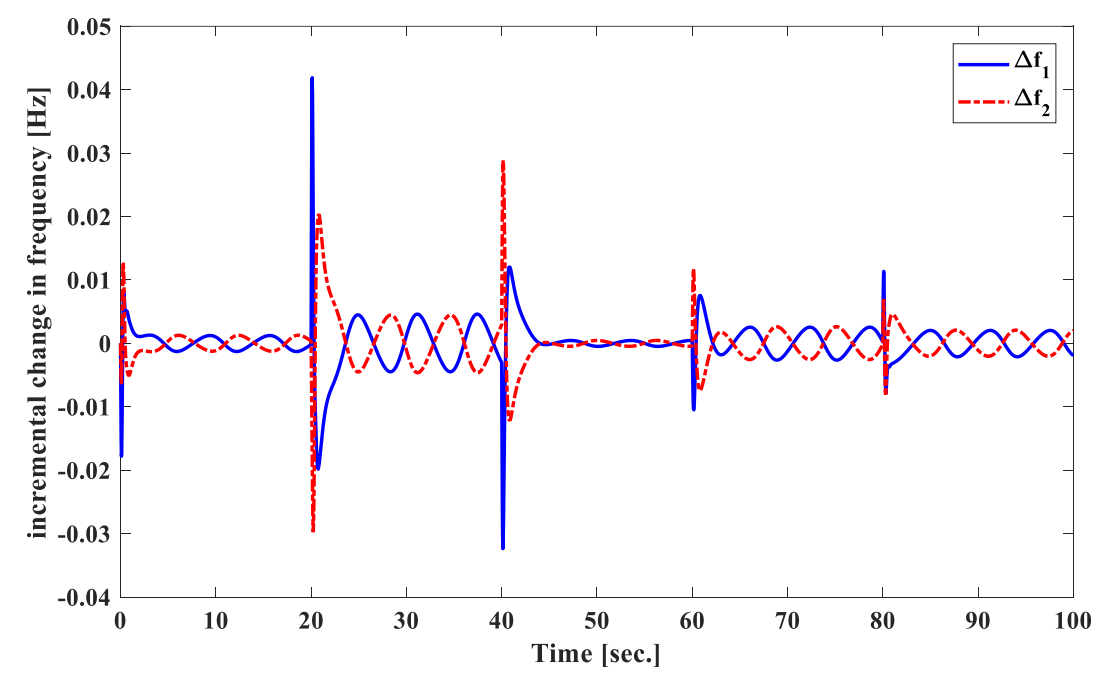

Figure 16. Frequency $[\mathrm{Hz}]$ of both control under load variations and the mismatched parameter uncertainties. 


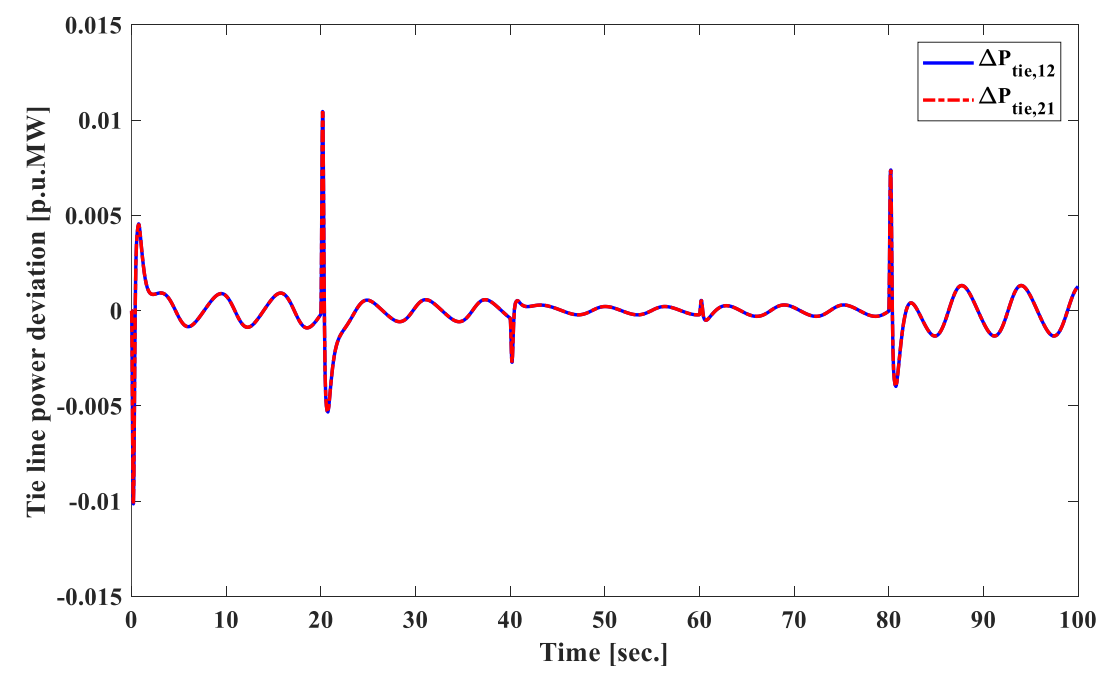

Figure 17. Tie-line power [p.u.MW] under load variations and the mismatched parameter uncertainties.

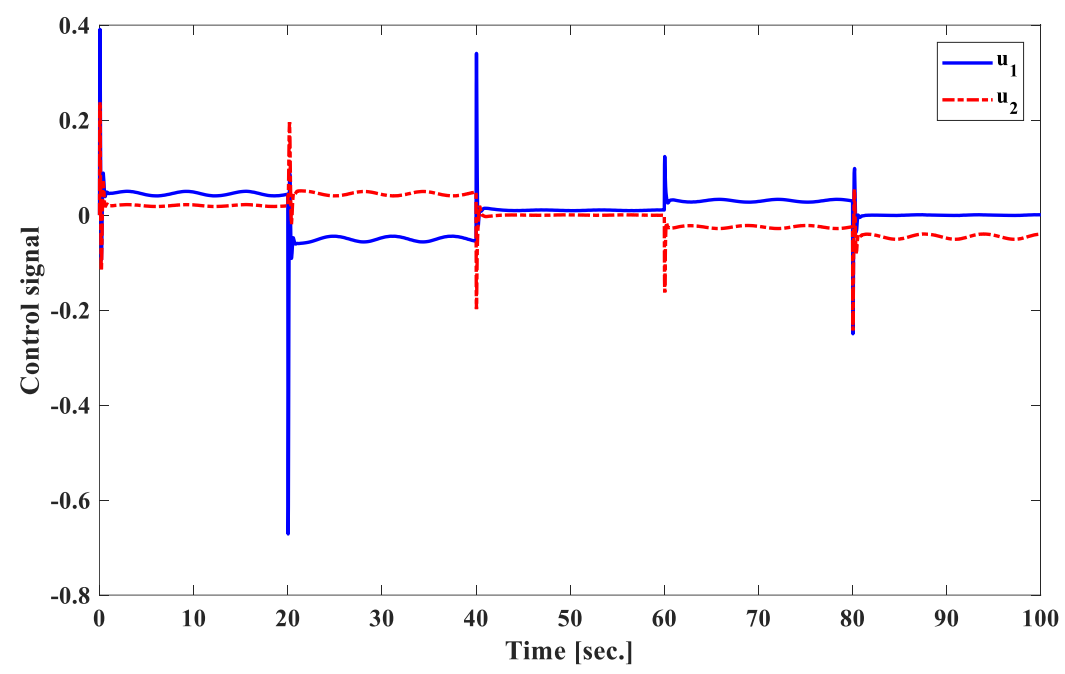

Figure 18. Control input [p.u.] under load variations and the mismatched parameter uncertainties.

Remark 4. By reporting of two simulation results above, the new second order variable structure control approach achieves affective response performance under various conditions such as the matched or mismatched uncertainties and load variations appearing in power networks. The suggested control scheme is applied and developed to remove and eliminate load disturbance in power system, restore the nominal point of system performance, and subtract the influence of load disturbances. This SOISMC is proved that have a good strategy to avoid chattering problem in SMC and achieve nominal system performance recovery.

\subsection{Simulation 3}

In this simulation, the aim is to compare with [33] to determine the validation of the proposed SOISMC. Therefore, the parameter of the system is obtained therein. A step load disturbance is set as 0.01 p.u. at $t=0 \mathrm{~s}$ in the first power control area follow by a step load disturbance is set as 0.01 p.u. at $\mathrm{t}=0 \mathrm{~s}$ in the second area and the uncertain parameters in the two-area benchmark system are assumed to vary within $15 \%$ of their nominal values. The performance of proposed SOISMC is investigated to compare with a novel adaptive sliding mode control method give in [33]. From the simulation report, Figures 19-22 confirm the validity of the proposed approach in terms of external disturbances and parameter changes. The increased load demand is $1 \%$ of the nominal values used in power system, 
the frequency deviates as shown by the under/overshoot in Figures 19 and 20 and restores the resisting nominal value in about $4.5 \mathrm{~s}$.

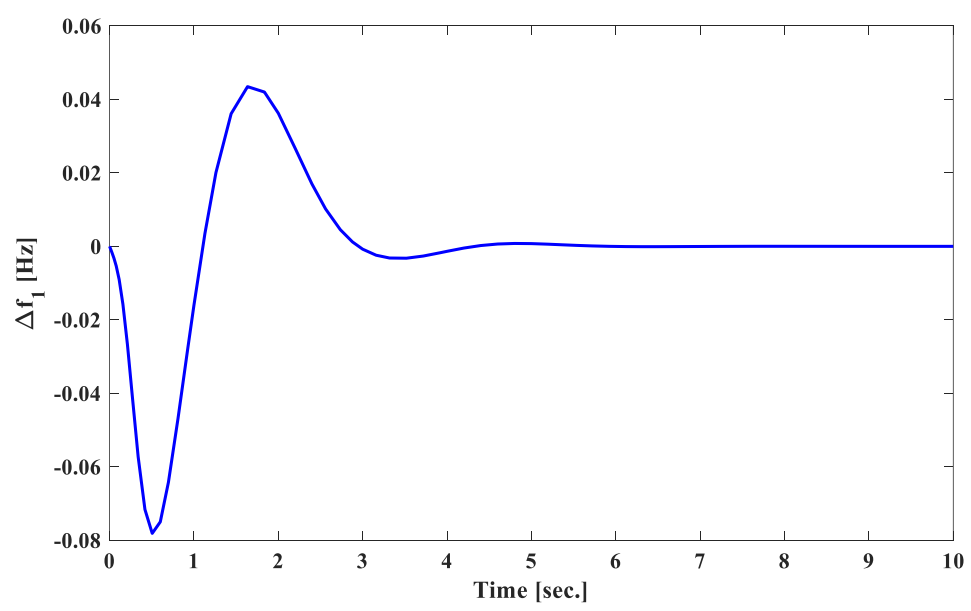

Figure 19. Frequency [Hz] of control area 1 under matched disturbances.

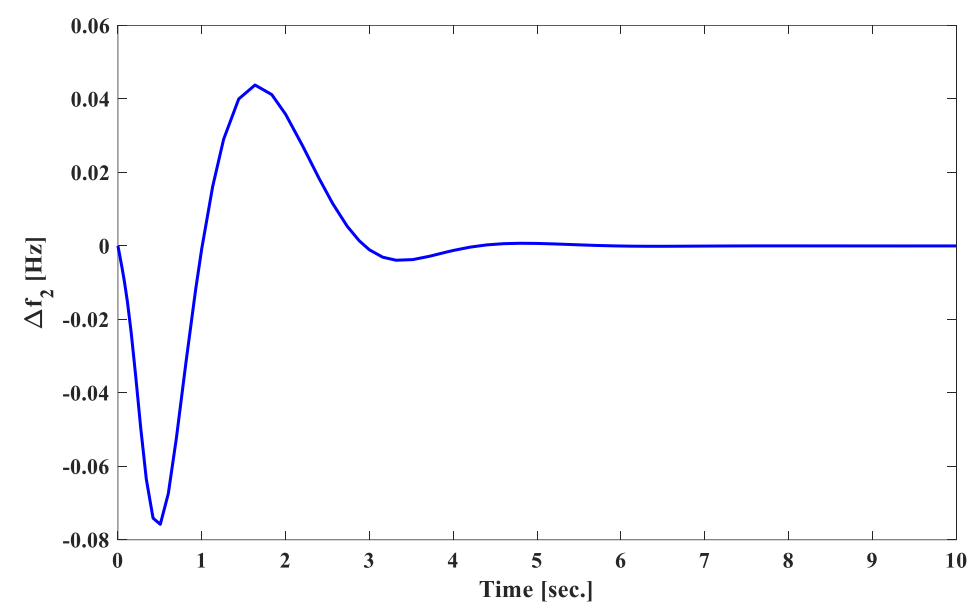

Figure 20. Frequency [Hz] of control area 1 under matched disturbances.

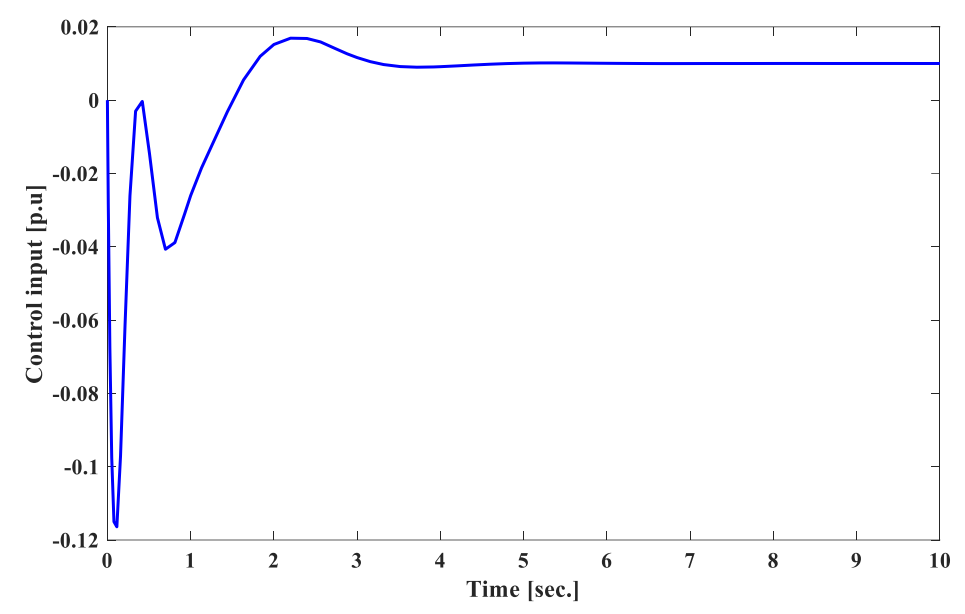

Figure 21. Control input [p.u.] of the first control area under matched disturbances. 


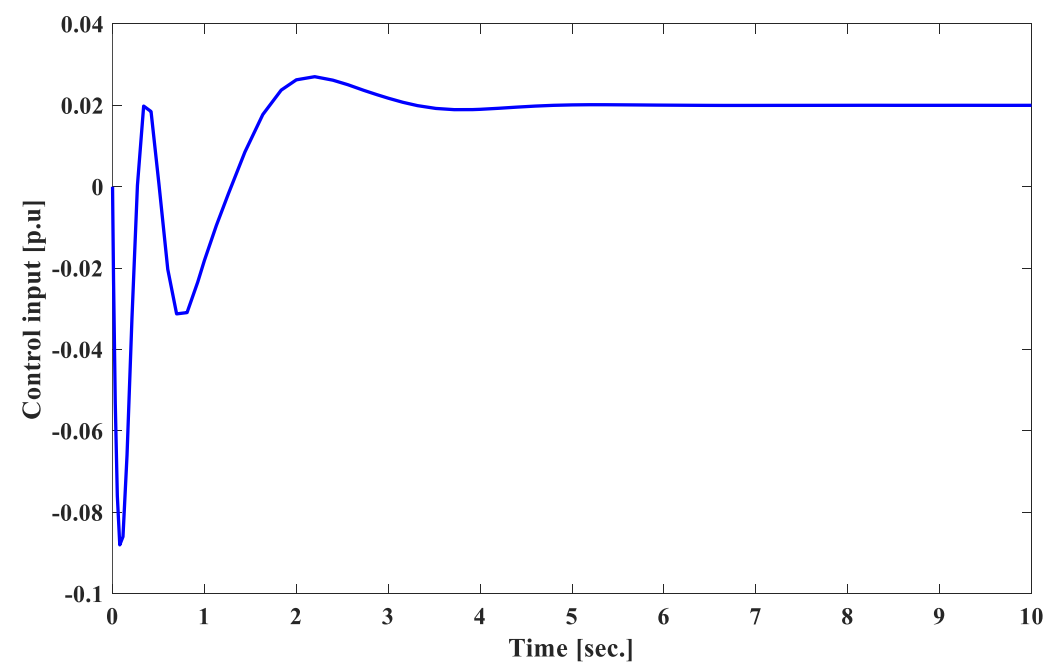

Figure 22. Control input [p.u.] of the second control area under matched disturbances.

Remark 5. In actuality, the parameter uncertainties always exist due to wearing out of components or variation of operating points. In the simulation 3, we study the LFC problem of the power network with load changes and parameter uncertainties, with the help of the proposed SOISMC, the frequencies of all areas return to the normal value in about $4.5 \mathrm{~s}$ after load disturbances occur. Therefore, the superiority of the proposed SOISMC in terms of chattering, overshoot and response time in comparison with the proposed adaptive sliding mode control method is also verified.

\section{Conclusions}

In conclusion, a new SOISMC scheme is introduced and proposed to build the controller to resolve and balance the active power of an interconnected multi-area power system. The suggested approach not only assured the stability of power networks but also considerably decreased the chattering problem in the power systems. An integral sliding surface-based second-order SMC is presented to ensure shortens the transient response of frequency, reduce the high overshoot and work out the priority problem of active power balance. The performance of an interconnected multi-area power system is proved in the solution of removing the chattering problem in comparison with the previous control method. Once again, to the best of our knowledge, the proposed SMC based on the FLC scheme shows excellent benefits, such as the advantages of robustness and usefulness of SMC and chattering elimination of FLC in real applications. Simulation results indicate that the powerful proposed control method removes the chattering phenomenon of the frequency occurring in this system without reducing the robustness of power system. By reducing the chattering in the control input, the proposed controller provides the correct signal to control mechanical inertia power to match the load change or demand, which is used fully for application in practical power networks to address high parameter uncertainties and load disturbances.

Author Contributions: Conceptualization V.V.H., P.T.T.; Methodology P.T.T., A.T.T., D.H.T.; Software A.T.T., D.H.T.; Validation V.V.H., P.T.T; Writing—original draft preparation P.T.T.; Writing—review and editing V.V.H.; Supervision B.L.N.M., T.M.N., P.-T.V. All authors have read and agreed to the published version of the manuscript.

Funding: This research is funded by Foundation for Science and Technology Development of Ton Duc Thang University (FOSTECT), website: http://fostect.tdtu.edu.vn, under Grant FOSTECT.2017.BR.05.

Conflicts of Interest: The authors declare no conflict of interest. 


\section{References}

1. Vijay, V.; James, C.; Paul, A.; Fouad, A. Power system control and stability; Wiley-IEEE Press: Hoboken, NJ, USA, 2019.

2. Devendra, K. Techniques and Its Applications in Electrical Engineering; Springer: Berlin/Heidelberg, Germany, 2008.

3. Fu, C.; Tan, W. Decentralized load frequency control for power systems with communication delays via active disturbance rejection. IET Gener. Transm. Distrib. 2018, 12, 1751-8687.

4. Zhang, Y.; Yang, T. Decentralized switching control strategy for load frequency control in multi-area power systems with time delay and packet lose. IEEE Access 2020, 8, 15838-15850. [CrossRef]

5. Guha, D.; Roy, P.K.; Banerjee, S. Load frequency control of interconnected power system using grey wolf optimization. Swarm Evol. Comput. 2016, 27, 97-115. [CrossRef]

6. Anwar, M.N.; Pan, S. A new PID load frequency controller design method in frequency domain through direct synthesis approach. Electr. Power Energy Syst. 2015, 67, 560-569. [CrossRef]

7. Farahani, M.; Ganjefar, S.; Alizadeh, M. PID controller adjustment using chaotic optimization algorithm for multi-area load frequency control. IET Control. Theory Appl. 2012, 6, 1984-1992. [CrossRef]

8. Sonkar, P.; Rahi, O.P. Tuning of modified PID load frequency controller for interconnected system with wind power plant via IMC tuning method. In Proceedings of the 4th IEEE Uttar Pradesh Section International Conference on Electrical, Computer and Electronics, Mathura, India, 26-28 October 2017.

9. Sahu, R.K.; Panda, S.; Rout, U.K. DE optimized parallel 2-DOF PID controller for load frequency control of power system with governor dead-band nonlinearity. Electr. Power Energy Syst. 2013, 49, 19-33. [CrossRef]

10. Chen, H.; Ye, R.; Wang, X.; Lu, R. Cooperative control of power system load and frequency by using differential games. IEEE Trans. Control Syst. Technol. 2015, 23, 882-897. [CrossRef]

11. Yousef, H.A.; AL-Kharusi, K.; Albadi, M.H.; Hosseinzadeh, N. Load frequency control of a multi-area power system: An adaptive fuzzy logic approach. IEEE Trans. Power Syst. 2014, 29, 1822-1830. [CrossRef]

12. Zeng, G.Q.; Xie, X.Q.; Chen, M.R. An adaptive model predictive load frequency control method for multi-area interconnected power systems with photovoltaic generations. Electr. Power Energy Syst. 2017, 10, 1840. [CrossRef]

13. Hao, Y.; Tan, W.; Li, D. Decentralized active disturbance rejection Control for LFC in deregulated environments. In Proceedings of the 33rd Chinese Control Conference, Nanjing, China, 28-30 July 2014.

14. Saxena, S.; Hote, Y.V. Load frequency control in power systems via internal model control scheme and model-order reduction. IEEE Trans. Power Syst. 2013, 28, 2749-2757. [CrossRef]

15. Rehiara, A.B.; Yorino, N.; Sasaki, Y.; Zoka, Y. An adaptive load frequency control based on least square method. Adv. Model. Control Wind Hydrog. 2020, 49, 220.

16. Gheisarnejad, M.; Khooban, M.H. Design an optimal fuzzy fractional proportional integral derivative controller with derivative filter for load frequency control in power systems. Trans. Inst. Meas. Control 2019, 1,1-19. [CrossRef]

17. Daneshfar, F. Intelligent load-frequency control in a deregulated environment: Continuous-valued input, extended classifier system approach. IET Gener. Transm. Distrib. 2013, 7, 551-559. [CrossRef]

18. Trip, S.; Cucuzzella, C.; De Persis, A.; Schaft, A.; Ferrara, A. Passivity-based design of sliding modes for optimal load frequency control. IEEE Trans. Control Syst. Technol. 2019, 27, 1893-1906. [CrossRef]

19. Li, H.Y.; Shi, P.; Yao, D.Y.; Wu, L.G. Observer-based adaptive sliding mode control of nonlinear markovian jump systems. Automatica 2016, 64, 133-142. [CrossRef]

20. Yang, B.; Yu, T.; Shu, H.; Yao, W.; Jiang, L. Sliding-mode perturbation observer-based sliding-mode control design for stability enhancement of multi-machine power systems. Trans. Inst. Meas. Control 2018, 41, 1418-1434. [CrossRef]

21. Prasad, S.; Purwar, S.; Kishor, N. Non-linear sliding mode load frequency control in multi-area power system. Control Eng. Pract. 2017, 61, 81-92. [CrossRef]

22. Mi, Y.; Fu, Y.; Wang, C.; Wang, P. Decentralized sliding mode load frequency control for multi-area power systems. IEEE Trans. Power Syst. 2013, 28, 4301-4309. [CrossRef]

23. Sheetla, P.; Shubhi, P.; Nand, K. H-infinity based non-linear sliding mode controller for frequency regulation in interconnected power systems with constant and time-varying delays, IET Generation. Transm. Distrib. 2016, 10, 2771-2784.

24. $\mathrm{Xu}, \mathrm{Y}$. A robust load frequency control scheme for power systems based on second order sliding mode and extended disturbance observer. IEEE Trans. Ind. Inform. 2018, 14, 3076-3086. 
25. Zheng, Y.; Liu, J.; Liu, X.; Fang, D.; Wu, L. Adaptive second order sliding mode control design for a class of nonlinear systems with unknown input. Math. Probl. Eng. 2015, 5, 1-7. [CrossRef]

26. Jianping, G. Load frequency control of a two area-power system with non-reheat turbines by SMC approach. J. Energy Power Eng. 2015, 9, 566-573. [CrossRef]

27. Mi, Y.; Fu, Y.; Li, D.; Wang, C.; Loh, P.C.; Wang, P. The sliding mode load frequency control for hybrid power system based on disturbance observer. Int. J. Electr. Power Energy Syst. 2016, 74, 446-452. [CrossRef]

28. Dianwei, Q.; Shiwen, T.; Xiangjie, L. Load frequency control for micro hydro power plants by sliding mode and model order reduction. Automatika 2017, 56, 318-330.

29. Dianwei, Q.; Shiwen, T.; Hong, L.; Xiangjie, L. Load frequency control by neural-network-based integral sliding mode for nonlinear power systems with wind turbines. Neurocomputing 2016, 173, 875-885.

30. Le, N.M.B.; Van, V.H.; Nguyen, T.M.; Tsai, Y.W. Decentralized adaptive double integral sliding mode controller for multi-area power systems. Math. Probl. Eng. 2018, 2018, 1-11.

31. Prasad, S.; Purwar, S.; Kishor, N. Load frequency regulation using observer based non-linear sliding mode control. Int. J. Electr. Power Energy Syst. 2019, 104, 178-193. [CrossRef]

32. Jianping, G. Application of full order sliding mode control based on different areas power system with load frequency control. ISA Trans. 2019, 92, 23-24.

33. Guo, J. Application of a novel adaptive sliding mode control method to the load frequency control. Eur. J. Control 2020, 12, 3050-3071. [CrossRef]

34. Khargonekar, P.P.; Petersen, I.R.; Zhou, K. Robust stabilization of uncertain linear systems: Quadratic stabilizability and $\mathrm{H}^{\infty}$ control theory. IEEE Trans. Autom. Control 1990, 35, 356-361. [CrossRef]

35. Boyd, S.; Ghaoui, E.L.; Feron, E.; Balakrishna, V. Linear Matrix Inequalities in System and Control Theory; SIAM: Philadelphia, PN, USA, 1994.

Publisher's Note: MDPI stays neutral with regard to jurisdictional claims in published maps and institutional affiliations. 